\section{Educational support for the dental workforce: a review of the first five years of Retaining and Returning Advisers in England}

\author{
J. Davies-Slowik, ${ }^{1}$ V. Firmstone ${ }^{2}$ and J. Frame ${ }^{3}$
}
IN BRIEF
- Retaining and Returning Advisers (RRAs) have become well-established dental educators in postgraduate dental deaneries across England.
- RRAs provide advice and educational support for a range of dental practitioners.
- RRAs are well-placed to respond to future workforce and educational priorities.

\begin{abstract}
Introduction Retaining and Returning Advisers (RRAs) were appointed to postgraduate dental deaneries in England in 2002 as part of the Government's strategy to retain the dental workforce and support return to practice following a career break. The study aimed to review RRAs' activities and consider the overall success of the RRA initiative five years from inception (2007). Design and methods A case study design, conducted in three phases, drawing on qualitative data. In Phase 1, semi-structured interviews were held with all RRAs in England $(n=12)$. Phase 2 involved an electronic survey of all 12 postgraduate dental deans in England $(n=10)$. In Phase 3, analysis was undertaken and a final report prepared. Results RRAs have been flexible in responding to the changing policy context, and devolved funding for the role to the local, deanery level. They have adapted to support more diverse target groups including those seeking vocational training equivalence and underperforming dentists. Future priorities were envisaged to be associated with primary care trusts' commissioning and quality assurance responsibilities, and supporting all members of the dental team. Conclusion RRAs have become well-established in deaneries and have made a successful contribution to addressing workforce and educational needs for a diverse group of practitioners.
\end{abstract}

\section{INTRODUCTION}

Over the last decade, the Labour government sustained a commitment to improve access to National Health Service dentistry $^{1,2}$ and this led to a range of targeted initiatives, ${ }^{3-5}$ culminating in the Dental Access Programme launched in March 2009. ${ }^{6}$ Aimed at strengthening recruitment and retention of dentists to the NHS dental service, one such initiative was the appointment of a new dental educator post, the Retaining and Returning Adviser (RRA), established in each of the postgraduate dental deaneries in England in early 2002.

Arising directly from recommendations in the Better opportunities for women

\footnotetext{
${ }^{1 *}$ Associate Dental Dean Performance Development, NHS West Midlands, St Chad's Court, 213 Hagley Road, Edgbaston, Birmingham, B16 9RG; ${ }^{2}$ Research Fellow, Centre for Research in Medical and Dental Education, School of Education, University of Birmingham, Birmingham, B15 2TT ${ }^{3}$ Emeritus Professor, Centre for Research in Medical and Dental Education, School of Education, University of Birmingham, Birmingham, B15 2TT Correspondence to: Dr Jane Davies-Slowik Email: jane.davies-slowik@westmidlands.nhs.uk Tel: +44 (0)1216952588
}

\section{Online article number E6}

Refereed Paper - accepted 11 November 2010

DOI: 10.1038/sj.bdj.2011.197

${ }^{\circ}$ British Dental Journal 2011; 210: E6 dentists report, ${ }^{7}$ the RRA dental educator role was financed centrally by the Department of Health (DH) (England) one day a week for three years. A total of 13 RRA posts to support dentists were created - one in each of the 12 postgraduate deaneries, plus an RRA for UK-trained dentists living overseas. At the same time, changes were introduced to strengthen the Keeping in Touch Scheme (KITS) for dentists on career breaks, and to extend the 'Getting Back to Practice' (GBtP) refresher courses for returning dentists. The primary goal of this enhanced package was to provide education, training and support to encourage dentists' return to practice following a career break and mitigate the risk of their leaving the profession.

A formative evaluation, conducted by the authors in the Centre for Research in Medical and Dental Education, University of Birmingham, and funded by the Department of Health (DH) for England, was undertaken during the RRAs' first 12 months $(2002 / 3) .^{8,9}$ This found, not surprisingly, that in the early phase of the RRAs' existence, their core target group was dentists on career breaks registered on KITS. Key activities included one-to-one support and organisation of GBtP courses, and other short refresher courses to help return to dentistry. However, some RRAs had started receiving enquiries from dentists with more diverse needs, for example, those experiencing ill health, refugee dentists, overseas-trained dentists wanting to work in the UK, those seeking vocational training (VT) equivalence, underperforming dentists, as well as local hygienists/ therapists who wanted advice on training and professional development. Our early evaluation highlighted the RRAs' potential to provide educational support for this broader range of dentists and dental care professionals (DCPs).

Four years on, in 2006/7, this study sought to revisit the RRA initiative across England, and review their role in light of funding and policy changes in the interim. Notably, in April 2005, at the end of the original three-year commitment for RRA posts, the centralised DH funding ceased. The financial arrangements for the RRA role devolved to local mainstream deanery budgets. In addition, from July 2006, the central administration of KITS and the coordinated GBtP courses ended. The strategic health authorities were instructed to 
determine their own local policy for keeping dentists in touch with the postgraduate deanery and the profession more widely. ${ }^{10}$ Despite these changes, all the RRA posts continued in postgraduate dental deaneries in England.

Also in this period (2002-2007), new dental workforce initiatives and strategic changes in dental policy impacted on the remit of the RRA role. For example, in further efforts to increase the NHS primary care dental workforce, programmes were DH-funded to recruit European Economic Area (EEA) dentists to the NHS, and accelerate registration of overseas-trained (nonEEA) dentists with the General Dental Council. ${ }^{11}$ Another key workforce policy aim was to reconfigure the skill-mix of dental teams by introducing extended duties for hygienists and therapists and permitting therapists to work in all sectors of dentistry, including the general dental service. ${ }^{12,13}$ Further, the DH for England's introduction of a new primary care dental contract in April 2006, with its requirement for all primary care dentists in England and Wales to be on a local performers list, brought changes in funding and contracting for dentists working in NHS primary care dentistry. ${ }^{14}$ For example, dentists wishing to join a performers list must show they have completed vocational training, be exempt because of having qualified in an EEA country, or demonstrate equivalence to vocational training via the competence assessment route. ${ }^{15}$ And notably, further changes are yet to come: with a new government in May 2010, the White Paper Equity and excellence: liberating the $N H S^{16}$ signals that a new commissioning process for primary care dental services is ahead.

In light of the dental policy reforms which took place between 2002 and 2007, and changes in DH funding of the RRA role, this study asked: How had the RRA dental educator role evolved in the five years since its initial launch? Had initial priorities for the role been retained? Had specific local and national policies shaped the RRAs' priorities? To what extent had the RRA role made a successful contribution to meeting dental workforce needs?

This paper sets out our key findings about the RRA role, five years on from its establishment in each postgraduate dental deanery, and considers the issues for the future of this dental educator role.

\section{DESIGN AND METHODS}

Given that the central purpose of this study was exploratory and descriptive, a case study research design was employed. The specific objectives were to:

- Provide an update of the RRA role identifying aims and key activities

- Review the development of RRA activities and explore the impact of changing policies, workforce priorities and funding streams

- Seek perspectives on the successes and future development of the RRA role.

The evaluation was conducted in three phases over 13 months, from November 2006.

In Phase 1 (November 2006-March 2007) all 12 RRAs across English postgraduate dental deaneries (plus the RRA for dentists working overseas) were approached to take part in the study. Twelve RRAs consented to be interviewed and semi-structured interviews were conducted by a member of the research team. In the interviews, RRAs were asked about their key target groups and activities, the impact of devolved funding on their role, their overall views of the RRA initiative, and observations about its likely future direction. All bar one of the interviews were conducted on the telephone and each lasted between 30 and 60 minutes. With the participants' permission, all interviews were tape-recorded and transcribed in readiness for qualitative data analysis.

Phase 2 (June 2007-September 2007) involved a survey of all 11 postgraduate dental deans in England; each was asked to respond to a structured set of open questions. These questions were distributed by email with an information sheet about the study and were designed to prompt open (free text) response to the issues raised. The response rate was excellent: ten out of 11 provided a detailed email reply. Specifically, postgraduate dental deans were asked to identify the most valuable aspects of the RRA role, to describe any changes in their responsibilities, to review the extent to which workforce issues had been addressed, and identify their plans for the future shape of the RRA role in the next 12 months (that is, during 2008).

In Phase 3, preparation of the Final Research Report commenced. ${ }^{17}$ In terms of analysis, the data collected were primarily qualitative. This was entirely fitting given the number of RRAs and the exploratory and descriptive nature of the enquiry. The analysis of transcript data and email responses was undertaken with rigour. A thematic approach to coding was adopted, whereby the qualitative data were scrutinised to identify main issues. ${ }^{18}$ In practice, summaries were developed for each RRA which were structured around the thematic issues arising from the interview transcripts. These summaries synthesised data from the two main sources (RRAs and postgraduate dental deans) and enabled triangulation of the study's principal research questions for each deanery.

\section{RESULTS}

\section{Support for diverse groups}

After five years in post, interviews with RRAs clearly demonstrated their role had expanded. Aside from supporting women on career breaks, other key target groups were emphasised. These primarily included overseas-trained dentists, poor performers, those seeking VT equivalence, and dental care professionals (DCPs).

To gauge the extent to which supporting these new groups was a substantive part of their activity, or just at the fringes of their time in role, the interviews asked each RRA about the nature and level of support given to each of the core groups mentioned. From their comments, we have distilled the relative emphasis given by each RRA to each of the five core target groups (Table 1). The four levels denote the extent to which each target group was:

1. Strongly featured in the interview

$(\bullet \bullet)$, thus a core priority for the RRA

2. Featured $(\bullet \bullet)$, activity undertaken but not the core priority

3. Featured weakly $(\bullet)$, limited support provided

4. Not featured (-).

Table 1 illustrates that most RRAs were engaged in supporting most of these five target groups, though to a varying extent. Nearly half (5/12, deaneries A-E) highlighted that they 'featured' the provision of support with all these key groups, as illustrated by the comment below:

'I am the second longest serving tutor in my deanery so I field all sorts of queries; I am the one-stop shop signposter for my 


\begin{tabular}{|c|c|c|c|c|c|}
\hline Deanery & $\begin{array}{l}\text { KITS/career } \\
\text { breakers }\end{array}$ & $\begin{array}{l}\text { Overseas- } \\
\text { trained }\end{array}$ & $\begin{array}{l}\text { Poor } \\
\text { performers }\end{array}$ & $\begin{array}{l}\text { VT } \\
\text { equivalence }\end{array}$ & DCPs \\
\hline A & $\bullet \bullet$ & $\bullet$ & $\bullet$ & $\bullet$ & $\bullet \bullet$ \\
\hline$B$ & $\bullet$ & • & $\bullet$ & $\bullet \bullet$ & • \\
\hline C & $\bullet \bullet$ & $\bullet$ & - & $\bullet$ & $\bullet$ \\
\hline D & $\bullet$ & $\bullet$ & $\bullet$ & $\bullet$ & $\bullet$ \\
\hline$E$ & $\bullet \bullet$ & $\bullet$ & • & • & - \\
\hline $\mathrm{F}$ & $\bullet \bullet$ & $\bullet$ & $\bullet$ & $\bullet$ & - \\
\hline G & $\bullet$ & $\bullet$ & $\bullet$ & $\bullet$ & - \\
\hline $\mathrm{H}$ & $\bullet$ & - & $\bullet \bullet$ & $\bullet$ & - \\
\hline 1 & • & $\bullet \bullet$ & - & • & - \\
\hline J & $\bullet \bullet$ & $\bullet$ & - & - & - \\
\hline $\mathrm{K}$ & • & $\bullet \bullet$ & • & • & - \\
\hline$L$ & $\bullet \bullet$ & - & - & • & $\bullet$ \\
\hline \multirow[t]{4}{*}{ Summary } & $\begin{array}{l}6 \text { strongly } \\
\text { featured }\end{array}$ & $\begin{array}{l}3 \text { strongly } \\
\text { featured }\end{array}$ & $\begin{array}{l}3 \text { strongly } \\
\text { featured }\end{array}$ & $\begin{array}{l}3 \text { strongly } \\
\text { featured }\end{array}$ & $\begin{array}{l}1 \text { strongly } \\
\text { featured }\end{array}$ \\
\hline & 4 featured & 5 featured & 3 featured & 4 featured & 1 featured \\
\hline & $\begin{array}{l}2 \text { weakly } \\
\text { featured }\end{array}$ & $\begin{array}{l}2 \text { weakly } \\
\text { featured }\end{array}$ & $\begin{array}{l}3 \text { weakly } \\
\text { featured }\end{array}$ & $\begin{array}{l}4 \text { weakly } \\
\text { featured }\end{array}$ & $\begin{array}{l}5 \text { weakly } \\
\text { featured }\end{array}$ \\
\hline & 0 not featured & 2 not featured & 3 not featured & 1 not featured & 5 not featured \\
\hline
\end{tabular}

deanery. It tends to be that if you don't know the answer ask [the RRA's name] and s/he will signpost - this is what I do.' RRA for Deanery E.

In terms of focus, the most common strongly featured $(\bullet \bullet)$ activity was with dentists on career breaks (6/12 strongly featured). Four RRAs considered this their single, main focus, and for another two deaneries other target groups were also strongly featured (deaneries A, E). Notably, in deanery A, the RRA strongly featured support for four groups, but this individual had other significant deanery responsibilities which overlapped with their RRA role. In most deaneries (10/12), however, RRAs had only one strongly featured group and this was with career break dentists, dentists requiring VT equivalence, support for overseas-trained dentists, or with poorly performing dentists.

Overall, the interviews suggested that although RRAs' contact with dentists on a career break had continued, the priority afforded to this group had declined over the five years. Most RRAs thought that this reflected the demise of the centrallyfunded KITS, but also, some felt, a lower level of demand for support from this group. However, as shown in Table 1, this was still the target group for which there was greatest unanimity among RRAs in their profile of activity. Moreover, changes in the primary care dental contract, particularly the introduction of Primary Care Trust (PCT) performers lists, were perceived to have increased the need for guidance in getting back to practice.

How the profile of activity had evolved for an RRA appeared to depend on local priorities, the strengths and interests of the RRA, and also any additional roles undertaken by the post-holder in the deanery. The emergence of local, deanery variation in the role, rather than a centrally-defined, more homogenous position, was a clear message from the interviews. One RRA felt that his/her priorities were set in a reactive rather than proactive way, relating to the current issues within the deanery.

'I think probably I'm more focused on $V T$ equivalence at the moment because that's actually happening here and now. So I think that's where we are. I think I am spending more time with them, and then poor performers and then the returners.' RRA for Deanery A.
Similarly, for another RRA, workforce issues and local needs determined the priority s/he gave to poor performance:

'The workforce issue doesn't seem to be what it was, I know and that's why again I think that it's far more important to look at the performance because I think there is a big risk of poor performance... I mean I think it is a high profile bit of the RRA role, and it is the risk area for Primary Care Trusts, for Strategic Health Authorities, local action, having some local way of dealing with performance concerns I think is vital.' RRA for Deanery D.

With the educational needs of different groups of dentists emerging, the interviews suggested that RRAs' priorities varied by deanery, but what kinds of activities were being undertaken by RRAs with these different groups?

\section{RRAs' main educational activities}

Much like the finding from the authors' early evaluation, ${ }^{8}$ RRAs' main educational activities distilled into one-to-one support and course organisation. Whether face-to-face, by telephone or by email, the purpose of one-to-one support included educational mentoring, needs assessments, career counselling, facilitating shadowing opportunities, passing on job vacancies, mailing out course information/brochures, and arranging access to resources (such as CD ROMs, phantom heads, and library materials). Some RRAs routinely ensured that a personal development plan (PDP) was used as a basis for discussion (Deaneries G and J), as described below:

'[I'd] arrange a face-to-face meeting but before that send them a PDP and ask them to work through that and have some idea of what they are doing so that the meeting is very much based around the PDP ... and then from that we move onto what their priorities are and where they are going to take things from there.' RRA for Deanery J.

RRAs' involvement in course provision varied in intensity. Interviewees spoke about facilitating access to existing courses in the deanery, commissioning and organising tailor-made courses (for example, Deanery D), and providing direct educational delivery themselves (Deanery G). For example, one RRA (Deanery G) explained: 
'I ran a surgery skills course ... and I ran it with the candidates taking the IQE [International Qualifying Examination] and the KITS together and I did two days. I made them cut crown prep and I showed them how to make temporary crowns and then they cut cavities and I showed them how to mix temporary materials and sort of very simple, basic, core surgery skills.' RRA for Deanery G.

Thus, the breadth of educational activity had not changed significantly for RRAs over the five-year period: many were still involved in both one-to-one and group programmes of support, although some had moved clearly into a commissioning or organising role for courses, rather than direct delivery.

\section{Perceptions about the overall value of RRAs}

Synthesising evidence from postgraduate deans and the RRAs, it is clear that the RRA role had become firmly embedded in postgraduate deanery structures in its first five years. RRAs were considered a skilled, flexible educational resource and there was general support for the continuation of their work from the postgraduate dental deans, despite changing priorities. One of the deans commented that:

'...priorities have now changed but the developing role in supporting PCTs in managing their performers' lists has resulted in a strengthening rather than a weakening of the RRA function.'

Many RRAs had been in post since the role's inception; each could readily demonstrate their comprehensive knowledge of dental workforce issues and highlighted the professional needs of their principal target groups. For RRAs with other posts in the deanery or local organisations, this expertise was felt to bring added value. All RRAs reported holding other responsibilities such as: dental practice adviser, adviser to national bodies (such as NCAS), other positions in the deanery (for example, associate dean, clinical tutor), clinical roles in general dental practice or the salaried service. This wealth of knowledge added to the collective experience of the RRAs across England, which RRAs shared with each other at national meetings and via an email network.
Perspectives from RRAs and dental deans presented a complex picture with regard to the value of RRA activity in increasing the number of active NHS dentists in the workforce. RRAs were generally positive about their impact on workforce issues, highlighting their contribution to the DH's workforce target, and the value of their educational support. Similarly, most deans were encouraging about RRA activity, though a small number raised questions about the measurable impact of their work with returners.

\section{The projected future for RRAs}

The study highlighted that the postgraduate dental deans and RRAs felt that the role had expanded to provide leadership in three core areas: VT equivalence assessments, supporting poorly performing dentists, and educational development support for the wider dental team. They identified these for sustained future development.

For many, this increased diversity had signalled the potential to recast the RRA job title (beyond returning and retaining dentists) for example, Workforce Support Adviser. The future was perceived to bring more generic titles which could provide formal recognition of their contribution to supporting the dental workforce more broadly.

\section{DISCUSSION}

In this study the RRA role has not been judged narrowly on its success in increasing the number of dentists returning or being 'retained' in the NHS dental workforce. Such a limited focus on one outcome measure is not sufficient to explore the range of education and support offered by RRAs across England. Moreover, in 2005, the Department of Health announced that its target to increase the NHS dental workforce had been attained. ${ }^{4}$ With the radical change in commissioning introduced by the 2006 NHS dental contract, recent evidence suggests that PCTs have successfully been able to tender for new dental services, with difficulties in attracting dentists only in specific areas, such as rural communities. ${ }^{19}$ In addition, with about one in five vocational dental practitioners reporting difficulty securing post-vocational training employment in 2008 (a proportion consistent in the two years previously), ${ }^{20}$ it could be argued that the shortfall of NHS dentists appears to have abated in most areas. Thus, the methodological challenge of measuring the increased number of NHS dentists was considered unnecessary and inappropriate for this study.

Five years on from its inception, the RRA role was still being carried out in all postgraduate deaneries in England, albeit with a different role title in some cases. Although many RRAs continued to support career break dentists returning to work, a strong message from the study was that RRAs' target groups had diversified in response to changing national and local priorities. The start of the new contract in 2006 and the associated performers list regulations imposed on PCTs have increased the workload for RRAs. Local responsibility given to PCTs to ensure that dentists are suitably trained and experienced has heightened PCTs' reliance on expert opinion in the deaneries. Thus, RRAs have increasingly provided educational support for new groups of practitioners including, for example, EEA dentists exempt from vocational training but in need of support as new providers of NHS dentistry.

Deaneries should be mindful of the potential training implications associated with any new responsibilities for RRAs. There is also value in clarifying the levels of support and priority they should afford to the breadth of groups supported, and maintaining evidence of activity and outcomes achieved with these new key target groups.

Local determination of systems and priorities also raises questions about equity of RRA provision across deaneries. As local priorities have increasingly determined the shape of RRA activities, there is potential for the dental workforce to receive differing levels of support from RRAs in different parts of England. This has been illustrated by the further development of roles within deaneries since the data was collected for the study.

\section{Implications for now and the future}

Although the workforce context for dentistry changed in the five year period studied, educational support for a diverse group of practitioners continues to be needed in deaneries. In particular, although the imperative to increase the number of NHS dentists has abated, Margaret Seward's 
goal to provide better support for women dentists remains relevant; some dentists taking career breaks need educational support to return to practice, and with increasing numbers of women dentists in the workforce, this looks set to continue.

With the introduction of DCPs as GDC registrants from 2008, it is also evident that educational support will be required to support DCP retention on the GDC register. The structure for supporting DCPs in each deanery is different and was beyond the scope of this study. However, support for DCPs will be increasingly important in light of extended roles for DCPs, registration with the GDC, and the responsibilities, including mandatory CPD, that registration brings. RRAs are well-placed to provide this support, or could help and advise others in this role (for example, DCP tutors). Such an educational role may be worthy of future study.

In addition, the GDC has stated its intentions to introduce revalidation - a process which requires dental professionals to demonstrate, on a regular basis, that they meet the standards required for continued registration. In order to revalidate, dentists will be required to produce a portfolio of evidence of performance over a five year period. The RRAs' experience, especially in portfolio review for vocational training by assessment (formerly known as VT equivalence), will be invaluable to those practitioners who may struggle with this process.

For the future, increased liaison with commissioners will be a priority for RRAs. The responsibility to commission dental care services is currently with the PCTs and assuring well performing dentists are on the performers lists is paramount. Moreover, given increased performance concerns raised about dentists with PCTs and the GDC, ${ }^{21}$ these cases need to be managed effectively. Deaneries, and particularly RRAs, if suitably resourced to support commissioners in this process, can provide an advisory and educational role for local dentists in need of remedial support. However, in the coming years, commissioning of primary care dental services will no longer be undertaken by PCTs.
The White Paper Equity and excellence: Liberating the NHS sets out far-reaching changes for the commissioning and delivery of health services in the coming years. From April 2012, primary dental care commissioning will be the responsibility of a new NHS Commissioning Board and while it is clear that ensuring high quality services remains paramount, exactly how this new independent body will operate and the effect on the existing Performers Lists is still to unfold. The White Paper also announced the consultation and piloting of a new dental contract and there is an intention to publish proposals for piloting this by the end of $2010 .{ }^{22}$ Thus, the RRA role will continue to evolve, and their historic evidence of flexibility in their first five years stands them in a strong position to respond to these future education and workforce priorities.

\section{CONCLUSIONS}

The RRA role changed considerably in its first five years. RRAs have become successfully established in deaneries, and there is a role for an educational adviser in each deanery to support diverse groups of dental practitioners.

In light of the 2006 NHS dental contract, and the devolved responsibility for the RRA role to deanery level, future priorities were predicted to be associated with the PCTs' new commissioning and quality assurance responsibilities, and this has been borne out by the breadth of support currently provided by RRAs. Supporting all members of the dental team was envisaged to become more important but this has not yet been realised. Revalidation is also ahead and this is likely to generate questions and educational issues from some dentists. In addition, further change is afoot in the coming years with the new Government's plans for the commissioning and delivery of health services, including the primary dental service. Dental educators, including RRAs, based in postgraduate dental deaneries are well-placed to respond to these developments.

We, the research team, would like to express our gratitude to Dame Margaret Seward for stimulating and supporting our interest in evaluating the RRA initiative. We acknowledge and thank the NHS West Midlands Workforce Deanery for funding this evaluation study. However, the views and opinions expressed are the authors' and do not necessarily reflect those of the funder. We also wish to thank the Retaining and Returning Advisers and the Postgraduate Dental Deans for their willingness to be interviewed and respond to surveys. Finally, particular acknowledgement is extended to Professor Alison Bullock for her leadership and support in the completion of this research and for her invaluable comments on earlier drafts of this paper.

1. Department of Health. Modernising NHS dentistry implementing the NHS plan. London: Department of Health, 2000.

2. Department of Health. The operating framework for the NHS in England 2010/2011. London: Department of Health, 2009.

3. Department of Health. The International Recruitment Project - recruiting dentists from Poland. London: Department of Health, 2004.

4. Department of Health. More dentists now, more dentists later. Press Release. Available from http:// www.dh.gov.uk. Accessed 25 May 2010.

5. NHS Primary Care Contracting and Department of Health. Primary care and community services: improving dental access, quality and oral health. London: Department of Health, 2009

6. NHS Primary Care Contracting. Dental access programme. www.pcc.nhs.uk/dentalaccess. Accessed 25 May 2010.

7. Seward M. Better opportunities for women dentists. London: Department of Health, 2001.

8. Firmstone V, Bullock A D, Bedward J, Frame J. An evaluation of the effectiveness of the Retaining and Returning Initiative in England. Birmingham: University of Birmingham Press, 2004.

9. Firmstone V, Bullock A D, Frame J, Bedward J. Supporting return to dentistry: a national evaluation of the Retaining and Returning Advisory Service. Br Dent J 2007; 203: 413-417.

10. Department of Health. Implementing loca commissioning for primary care dentistry. Factsheet 15: Keeping in Touch Scheme for dentists (KITS). London: Department of Health, 2006.

11. Department of Health. NHS dentistry: delivering change. Report by the Chief Dental Officer (England). London: Department of Health, 2004.

12. HM Government. The Dental Auxiliaries (Amendment) Regulation 2002. London: The Stationery Office, 2002.

13. General Dental Council. Extended duties for dental hygienists and dental therapists. Press release. London: General Dental Council, 2002.

14. Department of Health. NHS dentistry: options for change. London: Department of Health, 2002.

15. HM Government. The National Health Service (Performers Lists) Amendment Regulations. London: The Stationery Office, 2005

16. Department of Health. Equity and excellence: liberating the NHS. London: Department of Health, 2010.

17. Davies-Slowik J, Firmstone V, Bullock A, Frame J. Retaining and Returning Advisers in England: a review of their first five years in supporting the dental workforce. Birmingham: University of Birmingham Press, 2008.

18. Coffey A, Atkinson P. Making sense of qualitative data. London: Sage, 1996.

19. Review Body on Doctors' and Dentists' Remuneration. Thirty-Ninth Report. Norwich: The Stationery Office, 2010.

20. Review Body on Doctors' and Dentists' Remuneration. Thirty-Eighth Report. Norwich: The Stationery Office, 2009.

21. Mathewson $H_{1}$ Rudkin D. The GDC - lifting the lid. Part 4: fitness to practise. Br Dent J 2008; 205: 95-99.

22. Department of Health. New dental contract pilot proposals to be published in December. Press release. London: Department of Health, 2010. 